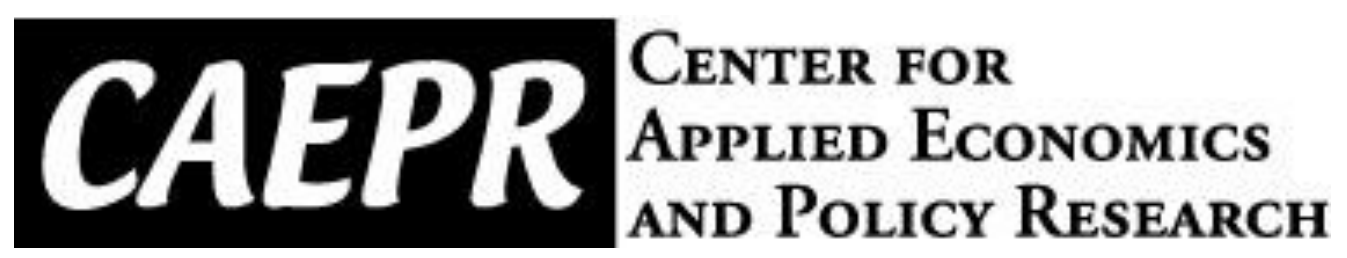

CAEPR Working Paper

\#2011-005

\title{
The Impact of the Internet on Information Searching and Demand for Traditional Information Resources
}

\author{
Anton Bekkerman and Gregory Gilpin \\ Montana State University
}

May 19, 2011

This paper can be downloaded without charge from the Social Science Research Network electronic library at: http://ssrn.com/abstract=1856056.

The Center for Applied Economics and Policy Research resides in the Department of Economics at Indiana University Bloomington. CAEPR can be found on the Internet at:

http://www.indiana.edu/ caepr. CAEPR can be reached via email at caepr@indiana.edu or via phone at 812-855-4050.

( 2011 by Anton Bekkerman and Gregory Gilpin. All rights reserved. Short sections of text, not to exceed two paragraphs, may be quoted without explicit permission provided that full credit, including $\odot$ notice, is given to the source. 


\title{
The Impact of the Internet on Information Searching and Demand for Traditional Information Resources
}

\author{
Anton Bekkerman and Gregory Gilpin*
}

The Internet is an efficient information search tool whose growth may have caused a structural change in information search and acquisition behaviors. This study investigates the effects of growing Internet accessibility on these behaviors. Using U.S. public library circulation counts to quantify changes in the use of information resources, the analysis indicates that greater Internet accessibility contributes to increased demand for traditional information sources. That is, a complementary relationship exists between Internet and traditional sources. Further, the results suggest that limiting Internet access can reduce the demand for traditional content. These outcomes imply that improvements in Internet accessibility can have profound effects on human capital development.

KEYWORDS: circulated materials, high-speed Internet access, Internet use, ME-GMM, public libraries, information search behavior

JEL classification codes: H52, L86, C33, L31

* Anton Bekkerman and Gregory Gilpin are assistant professors in the Department of Agricultural Economics and Economics at Montana State University. Senior authorship is shared. 


\section{The Impact of the Internet on Information Searching and Demand for Traditional Information Resources}

The Internet has become an indispensable tool for locating and acquiring information. This is primarily due to a rapid expansion of both Internet accessibility and content during the latter part of the 2000s. For example, the number of residences using high-speed Internet grew from 1.7 million in 1999 to 79 million in 2008 (Federal Communications Commission). ${ }^{1}$ Furthermore, Internet content grew from one billion unique web pages in 2000 to over one trillion by 2008 (Google Blog 2008). This accessibility and content growth has had broad impacts on the behaviors of individuals and businesses. Numerous studies provide empirical evidence of these impacts in labor markets, economics development, and education. ${ }^{2}$ However, these studies do not explicitly address the underlying reasons for these impacts: individuals' responses to competing information resources brought about by increased Internet accessibility. A better understanding of these responses may be attained by modeling and quantifying changes in information search and acquisition behaviors toward traditional and Internet information resources.

The impact of growing Internet access on individuals' information search and acquisition behaviors may be revealed through changes in individuals' demands for existing information content, available in books and other traditional information sources. One effect of Internet growth is a reduction in the use of traditional sources. The Internet offers a vast amount of broad information on almost any topic, substituting away from content traditionally obtained using existing information sources. The Internet may alternatively increase traditional content use due to an increase in the speed and efficiency of locating the information content. Evidence of either a

\footnotetext{
${ }^{1}$ High-speed Internet is characterized by a connection that provides access to the Internet with speeds of at least 200 kilobytes per second.

${ }^{2}$ For example, see Autor, Katz, and Krueger (1998); Crandall, Lehr, and Litan (2007); VanGaasbeck (2008); Kolko (2010).
} 
net substitution or net complementary effect can substantially improve the understanding of how Internet growth continues to affect the behavior of individuals and businesses. Consequently, this understanding can provide important inferences about long-term economic impacts on human capital development as a result of expanding Internet accessibility and content.

Public libraries are ideal locations to investigate Internet impacts. Traditionally, libraries have been a low-cost resource for obtaining information content from sources including print, audio, video, and static electronic materials such as databases. In addition, libraries have also been a primary location to search for information. Studying the Internet's impact on the demand for these traditional information sources can help better understand economic effects of the Internet as another information source. We first provide a stylized depiction of structural change in the information content search and acquisition process resulting from the introduction of the Internet. We then describe the empirical specification for modeling the simultaneous decisionmaking process of both individuals and public libraries. This is done by modeling individuals who choose to use Internet and/or traditional information sources to obtain information content, libraries who choose to alter quantities of traditional content (i.e., collections), and how both sets of choices affect succeeding decisions of both individuals and libraries. Furthermore, by modeling the simultaneous availability of the Internet and traditional information sources, we explicitly account for trade-offs that individuals face when searching and acquiring information content.

Using the simultaneous decision model, we estimate the effect of residential Internet access on the demand for circulated library materials. The empirical analysis results provide evidence that changes in residential Internet accessibility affect individuals' information search and acquisition behavoirs. Specifically, increased residential Internet access contributes to a net increase in the quantities demanded of traditional information content. The complementary 
relationship suggests that individuals may use the Internet to enhance their information search process for content in traditional information sources. That is, the Internet permits individuals to engage in sequential information searches, first acquiring broad information on a particular topic on the Internet as well as the location of specific dense information in traditional sources. This finding reveals the importance of promoting further growth in Internet accessibility and content, because this growth contributes to long-term improvements in individuals' abilities to locate and acquire a greater amount of information.

\section{Information Search and Acquisition Process}

To model the information search and acquisition process, we assume that individuals seek to minimize costs associated with searching and acquiring information. ${ }^{3}$ These costs can be characterized by the following function:

$$
\mathscr{C}=f\left(E, H, T_{1} \ldots T_{N}, S_{1} \ldots S_{M}\right)
$$

The term $E$ represents an individual's existing knowledge about a topic and $H$ is the individual's human capital associated with skills for locating and acquiring information. Larger amounts of existing knowledge and search skills are expected to reduce an individual's search costs. The set of terms $T_{1} \ldots T_{N}$ characterize the $N$ number of available resources and tools for performing information searches. Increases in the quantity of search resources are also expected to lower search costs. Lastly, the terms $S_{1} \ldots S_{M}$ denote $M$ available information spaces containing sources of information content, $\Omega$. An information space can therefore be characterized as $S_{m}=$

\footnotetext{
${ }^{3}$ Existing information science research has referred to this assumption as the principle of least effort (Zipf 1949). Buckland and Hindle (1969), Mann (1993), Bierbaum (1990), and Gratch (1990) apply this principle in describing information seeking behavior. Furthermore, Fisher, Erdelez, and McKechnie (2005) and Case (2007) provide comprehensive overviews of other information seeking models that have been proposed in the information science literature. The information search model presented in this study is congruent with these existing models.
} 
$\sum \Omega$.

Information contained in each source, $\Omega$, can be described by the breadth and density of knowledge about a topic. Information breadth describes the range of knowledge and density denotes the level of detail and complexity of knowledge. For example, a text intended for an introductory economics course encompasses information on many different topics of economics (broad information source), but does not provide much detail about any particular topic (low information density). Conversely, a text focusing on a single economics topic (narrow information source) provides a lot of detail and complexity about that topic (high information density). Generally, breadth and density are inversely related, such that an information source containing broader knowledge about a topic will include less detail and complex information about that topic.

Information spaces are assumed to contain information sources with comparable information breadth and densities. This allows information spaces to be ranked according to the characterization of information content in each space. For example, $S_{1}$ denotes a space containing information sources with very broad and low density content, and $S_{M}$ represents a space with narrow and dense content. Therefore, the breadth of information is monotonically decreasing and density is increasing with information space rank.

An objective of information searches is locating and acquiring information content about a particular topic with a desired breadth and density of information. Individuals are assumed to minimize costs associated with information searches by performing a sequential search process. First, individuals use their existing knowledge, $E$, about a topic to select an information space in which to perform an initial search for information content. Individuals with little or no existing knowledge will likely choose an information space with the broadest and least dense information sources. These sources provide general information about the topic and direct the 
individual to more dense information sources. Less dense information spaces likely contain information about more dense information sources (e.g. citations). Alternatively, individuals who have existing knowledge may choose an initial information space with narrower and denser information sources. Next, if more narrow, dense information is desired, then individuals use their search skills, $H$, and information from the lower ranked information space to move to a higher ranked information space, which contains sources with narrower and denser content. This sequential process continues across information spaces until individuals reach a space with sources containing the desired breadth and density of information about a topic. By using broad, less dense information available in lower ranked information spaces, individuals follow an optimal search path for locating and acquiring more dense information, minimizing their search costs. ${ }^{4}$

A visualization of a sequential search process is depicted in Figure 1. For a particular topic, the figure presents four information spaces containing information source with different information breadths and densities. In information space 1 (top-most space), the associated information sources contain very broad and least dense information content. This space is represented by a wide (broad) and thin (least dense) block. Conversely, information space 4 is characterized by narrow, thick blocks, which denote sources with the least broad and most dense information. Individuals with little existing knowledge about a topic and who want to attain dense information would minimize search costs by seeking initial information from sources in space 1, and sequentially following search paths (arrows in Figure 1) to locate an information source of desired breadth and density. In the figure, individuals who minimize their search costs are those that follow the least number of search paths from the initial information space to the

\footnotetext{
${ }^{4}$ This search process can be envisioned for any level of existing knowledge. Individuals with greater existing knowledge will likely begin a search process in a space containing information sources with narrower and denser content. This would reduce the number of sequential steps required to reach a space with the desired information density.
} 
terminal space.

Figure 1 can also be used to visualize and describe the impact of Internet growth on search costs. Prior to the Internet, traditional information sources such as printed and/or audio-video materials were used to obtain information of all densities. Therefore, individuals with minimal existing knowledge may have begun an information search in a space containing information both too narrow and too dense. Absence of prior broad information (and direction of successive search paths) may have caused individuals to choose erroneous information sources and search paths, substantially increasing the cost of searches. For example, suppose that an individual must begin a search in information space 3 because no other space with broader, less dense information is available. If the individual correctly chooses an information source in the space, then the correct information source in space 4 can be reached. However, because the individual's existing knowledge is likely insufficient for correctly choosing the necessary information sources, there is high likelihood of an error. Selecting an incorrect information source and reaching a subsequently erroneous information source in space 4 will likely require the individual to return to information space 3 and repeat the search process. This repetitive process can substantially increase search costs..$^{5}$

Growth of Internet content and accessibility has substantially improved individuals' ability to perform sequential searches. The Internet can be characterized as an information space containing an almost limitless number of sources with broad information of relatively low density. In Figure 1, we depict the Internet as information space 1. In this space, individuals can learn the most broad information about a topic and gain insight into the optimal search path for more narrow, denser information. Therefore, individuals use information acquired on the Internet to effectively locate the information space and source with the desired information

\footnotetext{
${ }^{5}$ Although each incorrect iteration can increase existing knowledge, $E$, it is unlikely that this would be enough for an individual to quickly converge to the correct information choice at level 3.
} 
content. By providing an information space that can be used as an effective starting point for almost any information search, the Internet can improve the sequential search process and minimize individuals' search costs.

\section{Modeling the Demand for Information Sources}

Changes in individuals' information search behaviors caused by Internet growth may be characterized by two opposing effects on the use of denser, traditional information sources. ${ }^{6}$ One effect is a decrease in the demand for traditional information sources due to individuals' use of the Internet to more effectively locate and acquire broad, low-density information content. Rather than using multiple dense information sources to acquire a broad understanding of a topic, individuals acquire information using the Internet. An opposite effect is characterized by an increase in the demand for traditional information sources, because the Internet increases the efficiency of the sequential search process. Either of these two effects can dominate, altering the demand for traditional information sources. If the demand for traditional resources increases when individuals obtain access to the Internet, the Internet contributes to a higher overall demand for information content.

We estimate the impact of Internet growth on individuals' information search behaviors by quantifying the net effect of the Internet on the demand for traditional information sources. Specifically, we consider the impact observed in public libraries. We assume that individuals patronize public libraries to acquire information content and public libraries supply two types of information content sources: traditional sources and in-library Internet access. Traditional sources are represented by $K$ collections from which patrons can borrow items. Demand for

\footnotetext{
${ }^{6}$ Examples of traditional information source include non-fiction and fiction printed materials, academic and non-academic journals, or audio and video material not directly available on the Internet.
} 
each collection is characterized by annual circulation, which is a measure of the total number of times patrons borrow from the collection. Libraries also provide patrons with Internet content through public-access computers. Demand for in-library Internet use is characterized by the annual number of Internet sessions initiated by patrons. We assume that a library maximizes the use of all information sources, and the maximization is represented by the following aggregate demand function:

$$
\max _{\{Q\}} \mathcal{Q}\left(Q_{t}^{1}, Q_{t}^{2}, \ldots, Q_{t}^{J}\right) .
$$

In period $t$, the $j^{\text {th }}$ quantity demanded of information source $\left(Q_{t}^{j}\right)$ is expected to be a function of quantities demanded of other sources $\left(\mathbf{Q}_{\mathbf{t}}^{-\mathbf{j}}\right)$, the collections' sizes $\left(\mathbf{C}_{\mathbf{t}}\right)$, patrons' ability to access the Internet outside of the library $\left(O_{t}^{\text {net }}\right)$, and other factors $\left(\mathbf{X}_{\mathbf{t}}\right)$. The set of $J$ information source demand functions are denoted as follows:

$$
\begin{aligned}
& Q_{t}^{1}=D^{1}\left(\boldsymbol{Q}_{t}^{-1}, \boldsymbol{C}_{\boldsymbol{t}}, O_{t}^{n e t}, \boldsymbol{X}_{\boldsymbol{t}}\right) \\
& \vdots \\
& Q_{t}^{J}=D^{J}\left(\boldsymbol{Q}_{t}^{-J}, \boldsymbol{C}_{\boldsymbol{t}}, O_{t}^{n e t}, \boldsymbol{X}_{\boldsymbol{t}}\right) .
\end{aligned}
$$

Libraries are unable to alter available Internet content, and must therefore accept changes in Internet content as exogenous. However, libraries may be able to affect quantities of information content demanded through changes in quantities of traditional information sources (i.e., collections). Information sources can be directly altered by a library through changes in the stocks of each $k^{\text {th }}$ collection. The quantity of collection $C_{t}^{k}$ is expected to be a function of all other collection sizes $\left(C_{t}^{-k}\right)$, the proportion of total operating revenue contributed to 
the acquisition of new materials $\left(\sum_{k} P_{t}^{k} I_{t}^{k} / T R_{t}\right)$, capacity and budget constraints $\left(\bar{C}_{t}\right)$, total operating revenue, the collection's depreciation rate $\left(\delta^{k}\right)$, and the quantities demanded of traditional information and in-library Internet sources $\left(\boldsymbol{Q}_{t}\right){ }^{7} \quad$ The set of $K$ collections are denoted as follows:

$$
\begin{aligned}
& C_{t}^{1}=S^{1}\left(\boldsymbol{C}_{\boldsymbol{t}}^{-1}, \bar{C}_{t}^{1}, \sum_{k} P_{t}^{k} I_{t}^{k} / T R_{t}, T R_{t}, \delta^{1}, \boldsymbol{Q}_{\boldsymbol{t}},\right) \\
& \vdots \\
& C_{t}^{K}=S^{K}\left(\boldsymbol{C}_{t}^{-\boldsymbol{K}}, \bar{C}_{t}^{K}, \sum_{k} P_{t}^{k} I_{t}^{k} / T R_{t}, T R_{t}, \delta^{K}, \boldsymbol{Q}_{\boldsymbol{t}}\right) .
\end{aligned}
$$

Equation sets (3) and (4) specify a framework characterizing the relationship between patrons' quantities demanded of information sources and collection stocks. This framework indicates that changes in residential Internet accessibility can directly and indirectly affect demands for traditional information sources. Demands for traditional information sources may be directly affected by patrons' decision to use the Internet. Additionally, changes in traditional content demands can alter a library's decision about the size of collection stocks, which can further affect patrons' demands for information content.

\section{Issues in Estimation}

Quantifying the effects of residential Internet accessibility on the demands for traditional information sources requires consideration of three dynamics: (1) traditional and Internet content are simultaneously available to patrons; (2) patrons' decisions to use a particular information source may be endogenous to their use of alternative sources; and (3) demand for both types of

\footnotetext{
${ }^{7} \mathrm{~A}$ full description of factors affecting the size of a collection is available in the Appendix.
} 
information sources may be endogenous to collection quantities. Appropriately accounting for these dynamics requires that equation sets (3) and (4) be estimated simultaneously. The system of simultaneously estimated equations is represented as follows:

$$
\begin{aligned}
& Q_{l, t}^{1}=D\left(Q_{1, t-1}^{1}, \boldsymbol{Q}_{l, t}^{-1}, \boldsymbol{C}_{l, t}, O_{l, t}^{n e t}, \boldsymbol{X}_{l, t}\right)+\varepsilon_{l, t}^{1} \\
& \vdots \\
& Q_{l, t}^{J}=D\left(Q_{l, t-1}^{J}, \boldsymbol{Q}_{l, t}^{-J}, \boldsymbol{C}_{l, t}, O_{l, t}^{n e t}, \boldsymbol{X}_{l, t}\right)+\varepsilon_{l, t}^{J} \\
& C_{l, t}^{1}=S\left(C_{l, t-1}^{1}, \boldsymbol{Q}_{l, t}, \boldsymbol{C}_{l, t}^{-1}, \boldsymbol{V}_{l, t}\right)+\varepsilon_{l, t}^{J+1} \\
& \vdots \\
& C_{l, t}^{K}=S\left(C_{l, t-1}^{K}, \boldsymbol{Q}_{l, t}, \boldsymbol{C}_{l, t}^{-K}, \boldsymbol{V}_{l, t}\right)+\varepsilon_{l, t}^{J+K} .
\end{aligned}
$$

The set of equations $\left\{Q_{l, t}^{1}, \ldots, Q_{l, t}^{J}\right\}$ denotes the demands for $J$ information sources at library $l$ during period $t$. Quantities demanded of other sources $\boldsymbol{Q}_{l, t}^{-j}$ and collection stocks $\boldsymbol{C}_{l, t}$ are endogenous to the $j^{\text {th }}$ demand, and residential Internet accessibility $O_{l, t}^{\text {net }}$ and other factors $\boldsymbol{X}_{l, t}$ are exogenous to the $j^{\text {th }}$ demand. Equations $\left\{C_{l, t}^{1}, \ldots, C_{l, t}^{K}\right\}$ represent collection stocks of traditional information content. Stocks of the $k^{\text {th }}$ collection $\left(C_{l, t}^{k}\right)$ are endogenous to stocks of other collections $C_{l, t}^{-k}$ and quantities demanded $Q_{l, t}$, but exogenous to other explanatory factors. For notational simplicity, vectors $Z_{l, t}^{j}=\left[\boldsymbol{Q}_{l, t}^{-j}, \boldsymbol{C}_{l, t}, \boldsymbol{O}_{l, t}^{n e t}, \boldsymbol{X}_{l, t}^{j}\right]$ and $\boldsymbol{W}_{l, t}^{k}=\left[\boldsymbol{C}_{l, t}^{k}, \boldsymbol{Q}_{l, t}, \boldsymbol{V}_{l, t}^{k}\right]$ represent all endogenous and exogenous explanatory variables for the associated equations.

The error term $\varepsilon_{l, t}^{j+k}=\left(\mu_{l}^{j+k}+u_{l, t}^{j+k}\right)$ is comprised of two components: a fixed-effect component $\mu_{l}^{j+k}$, which represents unobserved, time-invariant factors affecting the use of information source $j$ or collection stock $k$; and a random disturbance component $u_{l, t}^{j+k} .{ }^{8}$ The

\footnotetext{
${ }^{8}$ If neither further lags of $Q_{l, t}^{j}$ nor lags of $X_{l, t}$ are significant after controlling for $X_{l, t}, Q_{l, t-1}^{j}$, and $\mu_{l}^{j+k}$, then the dynamic completeness condition on $\mu_{l}^{j+k}$ holds for all $j+k$ (see (Wooldridge 2002)).
} 
fixed-effect component can be removed using first-differencing. However, because the set of first-differenced explanatory variables $\Delta \boldsymbol{Z}_{l, t}^{j}$ and $\Delta \boldsymbol{W}_{l, t}^{k}$ contain factors that are endogenous to first-differenced measures of content use $\left(\Delta Q_{l, t}^{j}\right)$ and collection $\left(\Delta C_{l, t}^{k}\right)$, we cannot assume that $E\left[\Delta \boldsymbol{Q}_{l, t}^{j} \Delta u_{l, t}^{j}\right]=0$ and $E\left[\Delta \boldsymbol{C}_{l, t}^{k} \Delta u_{l, t}^{k}\right]=0$.

To appropriately identify endogenous components in the $\Delta \boldsymbol{Z}_{l, t}^{j}$ and $\Delta \boldsymbol{W}_{l, t}^{k}$ vectors, we use instrumental variables (IVs). In a panel data structure, IVs can be contemporaneous exogenous variables, lagged exogenous variables, and/or predetermined variables. Exogenous instrumental variables are those that are not used in explaining circulation or collection stocks. Predetermined instruments can be lagged values of $\Delta Q_{l, t}^{j}, Q_{l, t}^{j}, \Delta C_{l, t}^{k}$, or $C_{l, t}^{k}$. Selected predetermined IVs must satisfy the sequential exogeneity condition $E\left[\Delta \boldsymbol{Q}_{l, s}^{j^{\prime}} \Delta u_{l, t}^{j}\right]=0\left(E\left[\Delta \boldsymbol{C}_{l, s}^{k^{\prime}} \Delta u_{l, t}^{k}\right]=0\right)$ or $E\left[\boldsymbol{Q}_{l, s}^{j^{\prime}} \Delta u_{l, t}^{j}\right]=0\left(E\left[\boldsymbol{C}_{l, s}^{k^{\prime}} \Delta u_{l, t}^{k}\right]=0\right)$, where $s=1, \ldots, T-1$ and $t=2, \ldots, T$. Sequential exogeneity can be tested by modeling $\Delta Q_{l, t}^{j}$ and $\Delta C_{l, t}^{k}$ as functions of $\Delta \boldsymbol{Z}_{l, t}^{j}$ and $\Delta \boldsymbol{W}_{l, t}^{k}$, respectively, and the set of selected instrumental variables. Then, evaluating a Wald test under the null hypothesis that the parameters estimated for the included instrumental variables are equal to 0 . Failure to reject the null hypothesis provides evidence of sequential exogeneity.

The general approach for simultaneously estimating the set of equations $\left\{\Delta Q_{l, 1 t}^{1}, \ldots, \Delta Q_{l, t}^{J}, \Delta C_{l, t}^{1}, \ldots, \Delta C_{l, t}^{K}\right\}$ is multiple equation generalized method of moments (ME-GMM). Instrumental variables are first used to identify endogenous variables and a system of dynamic equations is then simultaneously estimated with all equations related through the error structure.

\section{Data Description and Empirical Specification}

The Institute of Museum and Library Services (IMLS) defines a public library to be an establishment under state laws or regulations. The Hawkins-Stafford Elementary and Secondary 
Improvement Amendment (1988) introduced federally-funded annual surveys for collecting information about public library characteristics and services. In each state, surveys are administered by the chief office of the state library agency. These surveys were initially supervised by the National Center for Educational Statistics (NCES), but the 2008 Presidential Budget Request appropriated funds for survey administration to be taken over by the IMLS; this administrative change did not alter the survey design or methodology for reporting survey results.

We use public use data from the 2004-2008 Public Libraries Surveys. These data contain information about three library outlets: central libraries, branch libraries, and bookmobiles. Interpretation of empirical results across these outlets may be unclear, because outlets may offer substantially different information sources and services. To avoid cross-outlet comparisons, we aggregate data across all library outlets to form a library system. Denoting $c$ to be a particular reported characteristic at each outlet, the value of $c$ for a library system $l$ at time $t$ is $c_{l, t}=\sum_{i=1}^{I} c_{i, l, t}$ where $I$ represents the total number of outlets associated with the library system. Patrons located in a library system's legal service area can use content in any outlet of that library system, but cannot use content in other library systems. We assume that the service area restriction ensures that content use measures are negligibly dependent across library systems. ${ }^{9}$

A balanced panel data set contains annual information on 9,082 U.S. public library systems. Variable descriptions and summary statistics are presented in Table 1. All continuous library characteristics (except wages, unemployment rates, the ratio of expenses on material acquisitions to total operating revenue) are divided by the total population of a library's legal

\footnotetext{
${ }^{9}$ Although patrons can use interlibrary loans (ILL) to borrow traditional materials from other library systems or pay for access to out-of-system libraries, these instances are extremely low relative to collection use in local library systems.
} 
service area. ${ }^{10}$ Demand for traditional library sources are measured using annual adult and children's circulation. Furthermore, access to residential Internet is measured as the number of Internet service providers (ISPs) available to patrons, reported bi-annually by the Federal Communications Commission. ${ }^{11}$ County-level per capita wages and unemployment rates are collected from the U.S. Bureau of Labor Statistics. ${ }^{12}$ Each modeled variable is standardized by subtracting the variable's mean and dividing by its standard deviation. That is, a standardized variable $\tilde{c}_{l, t}$ is calculated as $\tilde{c}_{l, t}=\frac{c_{l, t}-\bar{c}_{t}}{\sigma_{c, t}}$, where $\bar{c}_{t}$ denotes the mean and $\sigma_{c, t}$ the standard deviation of the variable across all library systems in period $t .^{13}$

\section{Empirical Specification}

The panel data are used to estimate the following system of simultaneous equations:

$$
\begin{aligned}
& \Delta Q_{l, t}^{a}=\rho^{a} \Delta Q_{l, t-1}^{a}+\boldsymbol{\theta}^{a} \Delta \boldsymbol{Q}_{l, t}^{-a}+\boldsymbol{\psi}^{a} \Delta \boldsymbol{C}_{l, t}+\phi^{a} O_{l, t}^{n e t}+\gamma^{a} \Delta \boldsymbol{X}_{l, t}+\Delta u_{l, t}^{a} \\
& \Delta Q_{l, t}^{c}=\rho^{c} \Delta Q_{l, t-1}^{c}+\boldsymbol{\theta}^{c} \Delta \boldsymbol{Q}_{l, t}^{-c}+\boldsymbol{\psi}^{c} \Delta \boldsymbol{C}_{l, t}+\phi^{c} O_{l, t}^{n e t}+\gamma^{c} \Delta \boldsymbol{X}_{l, t}+\Delta u_{l, t}^{c} \\
& \Delta Q_{l, t}^{n}=\rho^{n} \Delta Q_{l, t-1}^{n}+\boldsymbol{\theta}^{n} \Delta \boldsymbol{Q}_{l, t}^{-n}+\boldsymbol{\psi}^{n} \Delta \boldsymbol{C}_{l, t}+\phi^{n} O_{l, t}^{n e t}+\gamma^{n} \boldsymbol{\Delta} \boldsymbol{X}_{l, t}+\Delta u_{l, t}^{n}
\end{aligned}
$$

\footnotetext{
${ }^{10}$ Population data are adjusted by the IMLS to eliminate overlapping service areas.

${ }^{11}$ Although a better measure of residential Internet access can be envisioned, the number of Internet service providers is the best available indicator. Furthermore, the number of ISPs is strongly exogenous to patron and library behaviors and the measure has been used to represent residential Internet availability in numerous other studies. For example, see Crandall, Lehr, and Litan (2007); Kolko (2010).

${ }^{12}$ Demographic data by city or Zip code are preferred, but these data are not available. Because different library outlets are aggregated into a single library system, county-level statistics provide an appropriate proxy for demographics of a library system's service area population.

${ }^{13}$ By standardizing variables, marginal effects of an explanatory variable are measured in standard deviations. That is, an estimated marginal effect describes the change in standard deviations of the dependent variable from a one standard deviation change in the associated explanatory variable (Pindyck and Rubenfield 1997). The absolute values of estimated marginal effects can be ranked to indicate the relative importance of each modeled variable in explaining variation of the dependent variable.
} 


$$
\begin{aligned}
& \Delta C_{l, t}^{p}=\rho^{p} \Delta C_{l, t-1}^{p}+\boldsymbol{\psi}^{p} \Delta C_{l, t}^{-\boldsymbol{p}}+\boldsymbol{\theta}^{p} \Delta Q_{l, t}+\gamma^{p} \Delta V_{l, t}+\Delta u_{l, t}^{p} \\
& \Delta C_{l, t}^{o}=\rho^{o} \Delta C_{l, t-1}^{o}+\boldsymbol{\psi}^{o} \Delta C_{l, t}^{-o}+\boldsymbol{\theta}^{\boldsymbol{o}} \Delta \boldsymbol{Q}_{l, t}+\gamma^{o} \Delta V_{l, t}+\Delta u_{l, t}^{o} \\
& \Delta C_{l, t}^{v}=\rho^{v} \Delta C_{l, t-1}^{v}+\boldsymbol{\psi}^{v} \Delta C_{l, t}^{-\boldsymbol{v}}+\boldsymbol{\theta}^{\boldsymbol{v}} \Delta \boldsymbol{Q}_{l, t}+\gamma^{v} \Delta V_{l, t}+\Delta u_{l, t}^{v} .
\end{aligned}
$$

Superscripts indicate content and collection categories: $a$ denotes adult circulated materials, $c$ is children's circulated materials, $n$ is in-library Internet sessions, $p$ is printed materials, $o$ is audio materials, and $v$ is video materials. The estimable parameter vectors are represented by $\boldsymbol{\rho}, \boldsymbol{\theta}, \boldsymbol{\psi}, \phi$, and $\gamma$. Vectors $\boldsymbol{\theta}, \boldsymbol{\psi}$, and $\phi$ can be interpreted as marginal rates and marginal technical rates of substitution among demands for information sources and collection stocks. That is, the marginal rate of substitution between residential Internet accessibility and the use of the $j^{\text {th }}$ traditional content is represented by the marginal effect $\phi^{j}=\frac{\Delta Q_{l, t}^{j}}{\Delta O_{l, t}^{n, t}}$, and the marginal effect of Internet use on the $k^{\text {th }}$ collection stock is $\psi_{k}^{n}=\frac{\Delta C_{l, t}^{k}}{\Delta Q_{l, t}^{n}} \cdot{ }^{14}$

Exogenous variables explaining variation in content use $\left(\Delta \boldsymbol{X}_{l, t}\right.$ and $\left.\Delta O_{l, t}^{n e t}\right)$ include residential Internet access, annual visitation, attendance in library-hosted adult and children's programs, library square footage, and county unemployment rate. Exogenous factors affecting collection stocks $\left(\Delta \boldsymbol{V}_{l, t}\right)$ are the library's square footage, its annual operating revenues, ratio of collection acquisition expenses to total operating revenues, and the number of full-time library employees..$^{15}$ Additionally, county per capita wage is a demographic characteristic included in both $\Delta \boldsymbol{X}_{l, t}$ and $\Delta \boldsymbol{V}_{l, t}$.

In the simultaneously estimated model, instrumental variables (IVs) are chosen to identify the six endogenous variables: changes in circulated adult materials, circulated children's

\footnotetext{
${ }^{14}$ Because available data are annual, it is expected that libraries are able to alter input decisions throughout the year and that these variations are accounted for in the modeled variables. Similarly, effects of input changes on patrons' content use behavior is also reflected in the annual data.

${ }^{15}$ Changes in a library's square footage are used to indicate expansion or contraction of the library facility. This is used as a characterization of the facility component in the capacity constraint, as described in the Appendix.
} 
materials, in-library Internet use, printed material collections, audio collections, and video collections. Instruments are characterized as follows: the same set of instruments is used to identify each endogenous variable, the sequential exogeneity condition is satisfied, and the Basmann test (Basmann 1960) null hypothesis cannot be rejected, indicating that instruments are uncorrelated with the error term and are correctly excluded from the estimated equation. Selected predetermined instruments are third- and fourth-lagged levels of the six dependent variables, and exogenous IVs are third- and fourth-lagged levels of library square footage, per capita wage, unemployment rate, and the number of ISPs. ${ }^{16}$

\section{Analysis Results}

A visual analysis of time-series changes in per patron in-library Internet use and residential accessibility to broadband Internet provides useful insights about the rate and scale of Internet growth. Figure 2(a) shows the median number of Internet sessions per patron in all U.S. public libraries between 2004 and 2008. The figure indicates a continuous increase of in-library Internet use during the time period. Further, Figure 2(b) shows the proportion of U.S. ZIP codes in which individuals have access to four or more high-speed Internet service providers (ISPs) between 1999 and $2008 .{ }^{17}$ In the first five years (1999 to 2004), individuals living in an additional 32\% of U.S. ZIP codes gained access to four or more ISPs. During the next five years (2004-2008), availability of ISPs increased in another $45 \%$ of ZIP codes, resulting in over $94 \%$ of all U.S. ZIP codes with four or more high-speed Internet service providers in 2008. Jointly, Figures 2(a) and 2(b) show that access to the Internet and its use as a library information tool has rapidly

\footnotetext{
${ }^{16}$ Although any number of lagged predetermined instruments can be selected, Ziliak (1997) shows that using too many overidentifying restrictions can cause estimators to have poor finite sample properties.

${ }^{17}$ Due to confidentiality reasons, data describing Internet service providers are censored for ZIP codes with one to three ISPs.
} 
increased.

To empirically analyze the impacts of expanding residential Internet accessibility and inlibrary Internet use, we estimate the model in equation (6) and present the results in Table 2. These results indicate that after controlling for factors such as income, greater access to residential Internet has a positive, statistically significant (1\% level) effect on the circulation of both adult and children's information sources. The statistically significant positive relationship indicates that patrons with higher access to residential Internet seek to supplement Internet content with traditional library content. Furthermore, this implies that greater residential Internet access does not crowd out use of traditional information content; rather, Internet access is complementary.

The complementarity between residential Internet access and use of traditional content may also be indicative of a structural shift in information search behaviors. Internet content contains general information on an almost limitless number of topics, but this content may not be sufficient for learning dense, detailed information about these topics. ${ }^{18}$ Obtaining detailed information often requires use of traditional information sources, such as those available in public libraries. Therefore, individuals would continue using Internet and traditional content as counterparts. The Internet may be used to gather initial, general information about a topic and to locate traditional information sources containing more in-depth content. Traditional sources are subsequently used to gain greater understanding of the topic.

These results can be directly related to the previously described model of the information search and acquisition process. Prior to the Internet, individuals with little existing knowledge on a topic may have engaged in information searches that were associated with large opportunity costs of time. Greater accessibility to the Internet, however, substantially lowered these costs,

\footnotetext{
${ }^{18}$ Furthermore, access to more detailed information may not be freely available due to copyright laws.
} 
allowing individuals to more effectively locate and acquire both broad and dense information content. The complementary relationship between residential Internet access and circulated library materials indicates that an improved search process contributes to higher demands for traditional information sources, which contain dense content. Consequently, this implies the complementarity can increase the use of information content sources of all breadths and densities. The long-term significance of this result may be manifest in increases of human capital, associated with greater accumulation of knowledge.

Other empirical results also indicate structural changes in individuals' information search behaviors. For an average U.S. public library system, in-library Internet use has a statistically significant negative effect on patrons' use of both adult and children's traditional information sources. Conversely, changes in children's circulation increase in-library Internet use and higher adult circulation has no statistically significant effect on Internet use. These sets of results indicate important relationships about patrons' choices between traditional and Internet sources in the library. Because the Internet can be a faster, more comprehensive information retrieval tool, patrons may seek to substitute traditional information sources for Internet content when the opportunity cost of time is high. That is, patrons may not be able to perform full sequential searches in a public library due to enforced constraints such as library operating hours, Internet session time limits, or restrictions on the number of daily Internet sessions per patron. These constraints may require patrons to choose between using in-library Internet content and traditional information sources.

Additionally, estimation results reveal that higher children's program attendance tends to increase circulation of children's material, but decreases adult material and in-library Internet use. The latter result is expected because many children's programs are targeted at promoting literary enthusiasm. Increases in either the library's capacity (square footage) or patron visitation 
positively affect the use of all content types. These variables may reveal amenity and other unobserved library characteristic effects on patron demands. Lastly, per capita wage parameters are statistically insignificant from zero, but higher unemployment rates tend to decrease the use of traditional content. Because unemployed patrons may have a high opportunity cost of remaining unemployed, their use of adult and children's circulation materials may decrease.

Table 2 also provides evidence of how changes in collection stocks affect factor demands for information content. Changes in all three collection stocks have statistically significant effects on Internet content use, with changes in printed material and audio collections positively affecting in-library Internet use, and increases in video collections reducing Internet use. Furthermore, changes in the stocks of printed material and video collections alter adult and children's circulated sources, respectively. The lack of statistically significant effects of the collection stock variables may suggest that a typical U.S. public library system may have limited abilities to affect traditional content use through changes in collection stocks. It is important to note, however, that because the available data do not provide a measure of collection quality, true effects of collection stock changes may be unobserved.

Parameter estimates corresponding to lagged dependent variables are negative and statistically significant in all six equations. Because all variables are represented as firstdifferences, the empirical results appropriately indicate the tendency of information source demands and collection stocks to follow a steady growth path. That is, an increase in either a demand or collection in period $t$ will be accompanied by a decrease in the demand or collection in period $t+1 .{ }^{19}$ For example, an escalation in circulation due to a particular fad will likely be

\footnotetext{
${ }^{19}$ Reversions to the growth path may not be as great in magnitude as the initial change in demand.
} 
followed by a decrease in circulation during the succeeding period. ${ }^{20}$ Furthermore, the estimated model indicates a statistically significant bi-directional complementarity between circulated adult and children's materials. This complementarity suggests that libraries may be able to improve overall use of traditional content by increasing either adult or children's circulation.

The estimated model also indicates that patrons' use of information content affects libraries' decisions to alter collection stocks. Increases in circulated children's materials lead to expansion of all collection stocks, changes of in-library Internet use positively affect audio stocks and negatively affect video collections, and higher use of adult circulated materials reduces all collection stocks. The negative relationship between adult circulation and collection size may indicate that higher adult circulation increases the rate of content depreciation, causing faster deterioration of collection stocks. Capacity constraints are also statistically significant in affecting collection stocks. Increases in a library's physical capacity (square footage) and budget capacity (total operating revenue) have positive, statistically significant effects on all collections sizes. Conversely, increasing the number of full-time library employees substitutes library funds away from collection acquisitions, reducing all traditional content collections.

In addition to providing statistical significance and direction measures of the estimated marginal effects, absolute values of parameter estimates can be used to rank the importance of each variable in explaining variation of information source demands and collection stocks. Not surprisingly, the most important factors in changing the demands for a particular source are the quantities demanded of other sources. The next most important factors are changes in collection size and patron visitation, followed by attendance of library-sponsored programs, accessibility

\footnotetext{
${ }^{20}$ There are numerous examples that characterize this phenomenon. Two prominent cases during the 2000s include the publication of the Harry Potter (Rowling 1997) book series and popularization of the Internet social networking service Facebook ${ }^{\complement}$. Immediately after each one of these events, public libraries most likely experienced abnormally high demands for circulated material and in-library Internet use. However, as these fads diminished, so did demands for library resources.
} 
to residential Internet, and unemployment rates.

\section{Conclusion}

The expansion of Internet content and reduction in access costs have led to widespread adoption as an information retrieval tool. This may primarily be due to the Internet providing a faster method for accessing broad information content and substantially reducing search costs through improved sequential search capabilities. Consequently, changes in the demand for Internet content may have altered individuals' and firms' decisions to use existing information sources. This study is the first to quantify these changes through an analysis of U.S. public libraries. Specifically, we estimate how changes in the availability of residential Internet access affect patrons' demands for traditional information sources in public libraries. Furthermore, we measure how these changes affect libraries' decisions to provide traditional information sources and the effects of these decisions on patrons' demands.

Results of the empirical estimation indicate that Internet access contributes to changes in information search and acquisition behavior. Specifically, increases in residential Internet access lead to increases in the demands for traditional information sources. One important implication is the potential positive relationship between Internet access and long-term human capital development through more effective acquisition of information. Therefore, public and private initiatives promoting an expansion of Internet access can substantially contribute to economic and welfare effects associated with human capital development. ${ }^{21}$ Conversely, limiting individuals' abilities to access Internet content can lead to reductions in the demands for both Internet and traditional information content. Examples of such limitations include net neutrality

\footnotetext{
${ }^{21}$ For example, the National Broadband Plan (2009) directs the Federal Communications Commission (FCC) to ensure that all Americans have access to high-speed residential Internet. In the majority of cases, this initiative will likely benefit rural communities most, because high-speed Internet access in these locations is limited.
} 
policies, Internet censorship laws, and Internet accessibility restrictions.

Undoubtedly, Internet growth will continue to provide more effective tools for searching and acquiring information. Outcomes of this study advance the understanding of how the associated changes and improvements in the information search process can lead to positive economic impacts. Specifically, empirical results indicate that, contrary to popular beliefs, the Internet is not crowding out the use of traditional information content; rather, Internet growth is contributing to higher demand for existing information sources. Furthermore, because many traditional information sources are supplied by public institutions such as libraries, these institutions may be vital to human capital development in the $21^{\text {st }}$ century. 


\section{References}

Autor, D., L. Katz, and A. Krueger. 1998. "Computing inequality: have computers changed the labor market?" The Quarterly Journal of Economics 113:1169-1213.

Basmann, R. 1960. “On finite sample distributions of generalized classical linear identifiability test statistics." Journal of the American Statistical Association 55:650-659.

Bierbaum, E. 1990. “A paradigm for the '90s.” American Libraries 21:18-19.

Buckland, M., and A. Hindle. 1969. "Library Zipf.” Journal of Documentation 25:54-57.

Case, D. 2007. Looking for Information: A Survey of Research on Information Seeking, Needs, and Behavior. London, U.K.: Elsevier, Ltd.

Crandall, R., W. Lehr, and R. Litan. 2007. "The effects of broadband deployment on output and employment: a cross-sectional analysis of U.S. data." Issues in Economic Policy: The Brookings Institution, http://www.brookings.edu//media/Files/rc/papers/2007/06labor_crandall/06labor_crandall.pdf.

Federal Communications Commission. Various years. "Number of Holding Companies Reporting High-Speed Subscribers by ZIP Code.” http://www.fcc.gov/wcb/iatd/comp.html.

Fisher, K., S. Erdelez, and L. McKechnie, eds. 2005. Theories of Information Behavior. Medford, NJ: Information Today.

Google Blog. 2008. "We knew the web was big." http://googleblog.blogspot.com/2008/07/weknew-web-was-big.html, accessed 09-10-2010.

Gratch, B. 1990. "Exploring the principle of least effort and its value to research." $C \& R L$ News $51: 727-728$. 
Institute of Museum and Library Sciences. Multiple years. "Public Libraries Surveys." http://harvester.census.gov/imls/data/pls/index.asp.

Kolko, J. 2010. "Does broadband boost local economic development?" Public Policy Institute of California, http://www.ppic.org/content/pubs/report/R_110JKR.pdf.

Mann, T. 1993. Library Research Models: A Guide to Classification, Cataloging, and Computers. New York: Oxford University Press.

Pindyck, R., and D. Rubenfield. 1997. Econometric Models and Economic Forecasts. Boston, MA: Irwin McGraw-Hill.

Rowling, J. 1997. Harry Potter and the Sorcerer's Stone, 1st ed. New York: A.A. Levine Books.

VanGaasbeck, K. 2008. "A rising tide: measuring the economic effects of broadband use across California.” The Social Science Journal 45:691-699.

Wooldridge, J. 2002. Econometric analysis of cross section and panel data. Cambridge, MA: MIT Press.

Ziliak, J. 1997. "Efficient estimation with panel data when instruments are predetermined: an empirical comparison of moment-condition estimators." Journal of Business and Economic Statistics 15:419-431.

Zipf, G. 1949. Human Behaviour and the Principle of Least Effort: An Introduction to Human Ecology. Cambridge, MA: Addison-Wesley. 
Table 1: Variable descriptions and summary statistics of U.S. public library systems

\begin{tabular}{|c|c|c|c|c|c|c|}
\hline Variable $^{a}$ & Description & & Mean & Std. Dev. & Maximum & Minimum \\
\hline ISPs & Available Internet service providers, annual & & 6.35 & 3.72 & 31 & 0 \\
\hline Adult circulation & Adult material circulation, annual & & 5.48 & 6.78 & 595.86 & 0 \\
\hline Child circulation & Children material circulation, annual & & 3.05 & 3.63 & 243.95 & 0 \\
\hline Internet use & Internet use, annual & & 1.47 & 2.37 & 104.00 & 0 \\
\hline Book collection & Printed material collection & & 6.77 & 10.81 & 673.08 & 0 \\
\hline Audio collection & Audio material collection & & 0.25 & 0.47 & 24.23 & 0 \\
\hline Video collection & Video material collection & & 0.35 & 0.78 & 36.31 & 0 \\
\hline Square feet & Square feet in library & & 1.33 & 2.18 & 109.22 & 0 \\
\hline Visits & Patron visitation, annual & & 6.17 & 8.71 & 430.97 & 0 \\
\hline Total operating revenue & Total operating revenue & & 37.39 & 43.41 & 1930.57 & 0 \\
\hline Expenses/Tot. oper. rev. & (Expenses on materials : tot. oper. rev) ratio & & 0.16 & 0.60 & 64.21 & 0 \\
\hline FTE employees & Number of full-time library employees & & 0.00 & 0.05 & 2 & 0 \\
\hline Wage per capita & County income & & 25,836 & 30,927 & 234,011 & 260 \\
\hline Unemployment rate & County unemployment rate & & $5.14 \%$ & $1.48 \%$ & $16.21 \%$ & $2.00 \%$ \\
\hline Child program attend. & Children program attendance, annual & & 0.13 & 3.65 & 116.89 & 0 \\
\hline Adult program attend. & Adult program attendance, annual & & 0.36 & 0.93 & 56.14 & 0 \\
\hline \multirow[t]{2}{*}{ Library area population } & Library service area population & & 31,509 & 125,737 & $4,045,873$ & 17 \\
\hline & Observations in sample: & 45,410 & & & & \\
\hline
\end{tabular}

${ }^{a}$ All variables (except wage, unemployment rate, and expenses/tot. oper. rev.) are per person located in a library's service area. 
Table 2: Results of Simultaneously Estimated Public Library Information Source Demands and Collection Stocks

\begin{tabular}{|c|c|c|c|c|c|c|}
\hline & \multicolumn{6}{|c|}{ Demand for Library Information Sources } \\
\hline & \multicolumn{2}{|c|}{ Adult Circulation } & \multicolumn{2}{|c|}{ Child Circulation } & \multicolumn{2}{|c|}{ Internet Use } \\
\hline & Estimate & t-Value & Estimate & t-Value & Estimate & t-Value \\
\hline Intercept & $-7.2 \mathrm{E}-6$ & -0.51 & $-2.6 \mathrm{E}-6$ & -0.16 & $-5.0 \mathrm{E}-6$ & -0.32 \\
\hline ISPs & $1.6 \mathrm{E}-5 * * *$ & 3.54 & $4.6 \mathrm{E}-5 * * *$ & 9.32 & 4.6E-6 & 1.14 \\
\hline Adult circulation $^{a}$ & $-5.3 \mathrm{E}-1 * * *$ & -94.15 & $0.48^{*}$ & 1.89 & 0.02 & 0.10 \\
\hline Child circulation $^{a}$ & $1.48 * * *$ & 9.40 & $-4.2 \mathrm{E}-1 * * *$ & -63.61 & $0.53 * * *$ & 2.95 \\
\hline Internet use $^{a}$ & $-2.0 \mathrm{E}-1 * *$ & -2.07 & $-6.2 \mathrm{E}-1 * * *$ & -3.03 & $-4.4 \mathrm{E}-1 * * *$ & -108.92 \\
\hline Square feet & $0.07 * * *$ & 21.87 & $0.05 * * *$ & 12.41 & $0.05 * * *$ & 13.96 \\
\hline Visits & $0.14 * * *$ & 27.42 & $0.11 * * *$ & 19.13 & $0.28 * * *$ & 58.09 \\
\hline Wage per capita & 2.94 & 1.29 & $-6.0 \mathrm{E}-1$ & -0.23 & $-2.2 \mathrm{E} 0$ & -0.92 \\
\hline Unemployment rate & $-5.0 \mathrm{E}-5 * * *$ & -3.31 & $-9.0 \mathrm{E}-5^{* * *}$ & -5.11 & $1.3 \mathrm{E}-6$ & 0.08 \\
\hline Print collection & $-2.4 \mathrm{E}-2$ & -0.43 & $0.57 * * *$ & 7.45 & $0.20 * * *$ & 3.06 \\
\hline Audio collection & 0.03 & 0.33 & $-2.8 \mathrm{E}-1$ & -1.59 & $0.22 *$ & 1.94 \\
\hline Video collection & $0.05 * *$ & 2.08 & 0.02 & 0.41 & $-3.4 \mathrm{E}-2 *$ & -1.77 \\
\hline Adult program attend. & $-5.7 \mathrm{E}-4 * * *$ & -4.34 & $-1.3 \mathrm{E}-3 * * *$ & -8.57 & $3.0 \mathrm{E}-4 * *$ & 2.51 \\
\hline Child program attend. & $-1.9 \mathrm{E}-2 * * *$ & -10.73 & $0.04 * * *$ & 18.74 & $-3.2 \mathrm{E}-2 * * *$ & -19.69 \\
\hline Test for overid. ${ }^{b}$ & 4.08 & {$[0.01]$} & 1.38 & [0.09] & 2.33 & [0.01] \\
\hline
\end{tabular}

Intercept

Print collection ${ }^{a}$

Audio collection ${ }^{a}$

Video collection ${ }^{a}$

Adult circulation

Child circulation

Internet use

Square feet

Total operating revenue

Expenses/Tot. oper. rev.

FTE employees

Wage per capita

Test for overid. ${ }^{b}$

(2)

\section{Printed Collection}

Estimate

$-2.0 \mathrm{E}-5$

$-4.8 \mathrm{E}-1 * * *$

$0.87^{*}$

$-1.5 \mathrm{E}-1 *$

$-5.5 \mathrm{E} 0 * * *$

$7.80 * * *$

0.38

$0.23 * * *$

$9.9 \mathrm{E}-7 * * *$

$-1.0 \mathrm{E}-5$

$-1.4 \mathrm{E}-1 * * *$

$15.33^{*}$

2.24

\section{t-Value}

$-0.37$

$-91.90$

1.77

$-1.90$

$-6.99$

11.87

0.68

15.13

17.35

$-0.62$

$-4.06$

1.91

[0.09]

\section{Collection Stocks}

\begin{tabular}{|c|c|c|c|}
\hline \multicolumn{2}{|c|}{ Audio Collection } & \multicolumn{2}{|c|}{ Video Collection } \\
\hline Estimate & t-Value & Estimate & t-Value \\
\hline$-1.0 \mathrm{E}-5$ & -0.31 & $-1.2 \mathrm{E}-4$ & -0.47 \\
\hline$-1.6 \mathrm{E}-1$ & -0.82 & $-4.0 \mathrm{E} 0 * * *$ & -4.55 \\
\hline$-5.0 \mathrm{E}-1 * * *$ & -77.78 & $12.92 * * *$ & 6.72 \\
\hline $0.38 * * *$ & 5.04 & $-6.4 \mathrm{E}-1 * * *$ & -58.61 \\
\hline$-3.9 \mathrm{E} 0 * * *$ & -6.17 & $-1.7 \mathrm{E} 1 * * *$ & -5.24 \\
\hline $3.60 * * *$ & 7.15 & $22.84 * * *$ & 7.66 \\
\hline $1.24 * * *$ & 3.45 & $-3.7 \mathrm{E} 0 * *$ & -2.17 \\
\hline $0.17 * * *$ & 17.83 & $0.24 * * *$ & 4.19 \\
\hline $3.9 \mathrm{E}-7 * * *$ & 6.71 & $3.4 \mathrm{E}-6 * * *$ & 15.48 \\
\hline$-3.3 \mathrm{E}-6$ & -0.14 & $-8.0 \mathrm{E}-5$ & -0.88 \\
\hline$-8.4 \mathrm{E}-2 * *$ & -2.40 & $-6.5 \mathrm{E}-1 * * *$ & -4.92 \\
\hline$-6.9 \mathrm{E} 0$ & -1.46 & $-5.9 \mathrm{E} 0$ & -0.19 \\
\hline 2.9 & {$[0.01]$} & 1.32 & {$[0.10]$} \\
\hline $\begin{array}{l}\text { Observatio } \\
\text { uared for }\end{array}$ & $\begin{array}{l}45,410 \\
\text { ated system: }\end{array}$ & 0.316 & \\
\hline
\end{tabular}

Weighted R-squared for estimated system: $\quad 0.316$

$* * *, * *, *$ indicate statistical significance at the $1 \%, 5 \%$, and $10 \%$ level.

a "Adult circulation," "Child circulation," "Internet use," "Print collection," "Audio collection," and "Video collection" indicate parameter estimates on lagged dependent variables when each corresponds to the column's dependent variable. For example, in the Adult Circulation column, "Adult circulation" represents "Adult circulation t-1 ".

${ }^{b}$ Basmann (1960) test for overidentifying restrictions. The test statistic is reported and the value in brackets represents the associated p-value. 


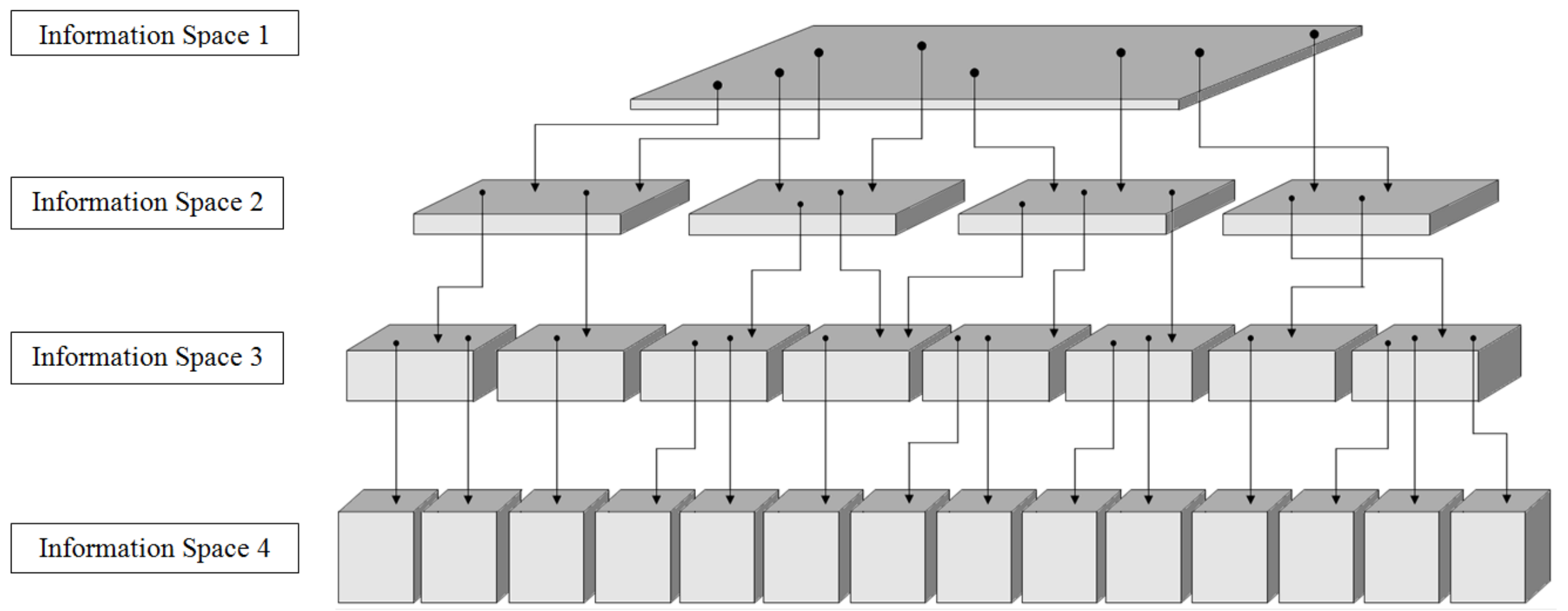

represents an information source. Wider, thinner blocks denote sources containing broad, less dense information content, generally containing little detail about any particular topic (e.g. the Internet). Narrow, deeper blocks represent sources containing narrow, dense information content about a specific topic (e.g. manuals, academic journals).

$\rightarrow$ : represents a path from a broader, less dense source to a narrower, more dense information source. Information available in a higher (more broad) information space can lead to space containing sources with narrower and denser information content. 
Figure 2: Changes in Use of In-Library Internet Content and Access Outside of Public Libraries

(a) Median Internet Use per Patron, 2004 - 2008

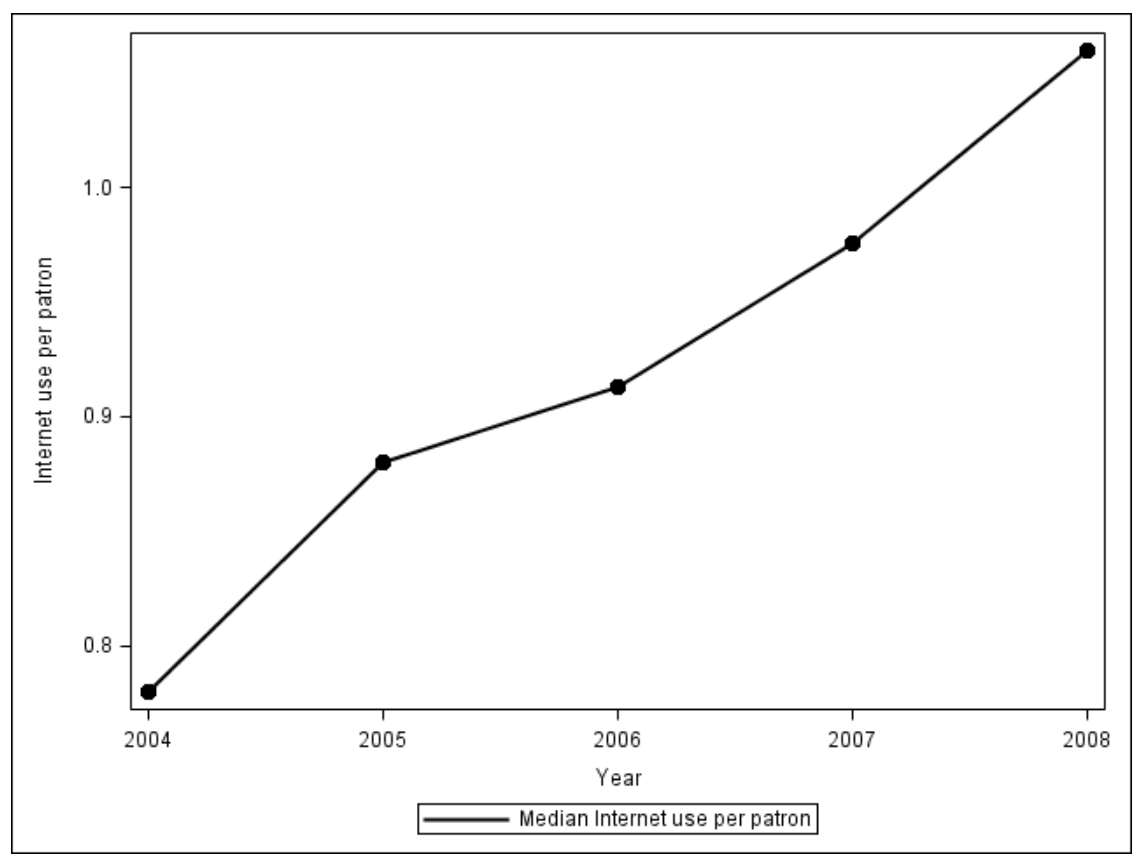

(b) Proportion of U.S. Zip Codes with Four or More Internet Service Providers,

$$
1999-2008
$$

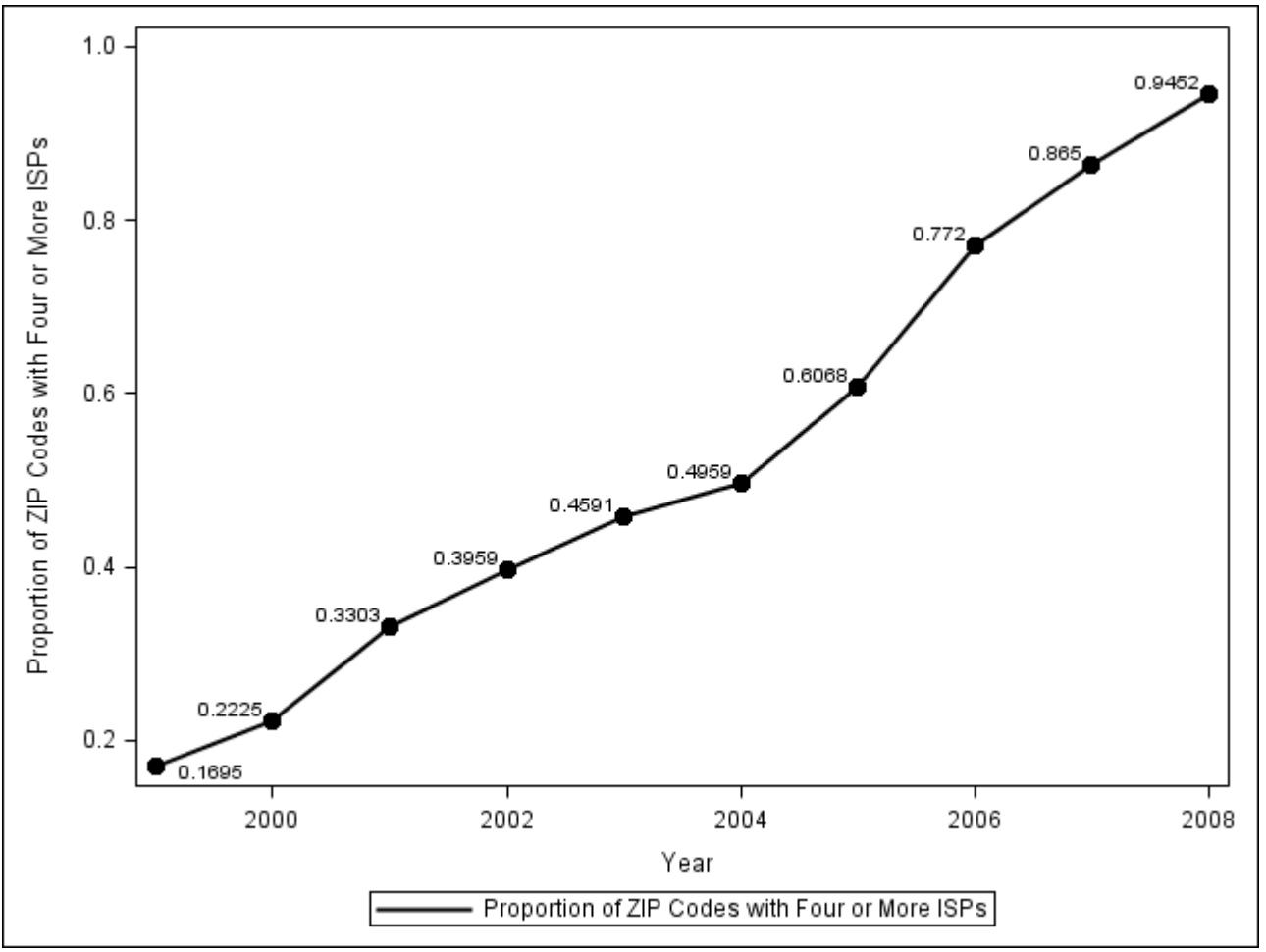




\section{Appendix}

Changes in the stocks of the $k^{\text {th }}$ collection $\left(C_{t}^{k}\right)$ can be represented by the following laws of motion equation:

$$
C_{t}^{k}=I_{t}^{k}+\left(1-\delta^{k}\right) C_{t-1}^{k}
$$

The term $I_{t}^{k}$ denotes the acquisition of new materials for collection $k$ (physical investment), and $\delta^{k}$ is the collection's depreciation rate. The depreciation rate can be interpreted as normal deterioration of collection materials as a result of circulation and use.

When making decisions about altering collection stocks, libraries are subject to two constraints: a physical capacity constraint and a budget constraint. The capacity constraint is comprised of a collection capacity component and a facility component, denoted, respectively, as follows:

$$
C_{t}^{k} \leq \bar{C}_{t}^{k}
$$

and

$$
\sum_{k} \bar{C}_{t}^{k}=\bar{C}_{t}
$$

Equation (8) indicates that the total size of the $k^{\text {th }}$ collection $\left(C_{t}^{k}\right)$ can not exceed the maximum physical capacity allocated to that collection $\left(\bar{C}_{t}^{k}\right)$. The facility component shown in equation (9) implies that the maximum capacity of all collections cannot be greater than the total physical capacity of the library $\left(\bar{C}_{t}\right)$. If a library has filled its total physical capacity, then increasing the size of a particular collection requires the library to reallocate space among existing collections. reduce a collection, or increase $\bar{C}_{t}$ through facility expansion

Decisions to change collection stocks may also be affected by the library's budget constraint, 
represented by the following equation:

$$
\sum_{k} P_{t}^{k} I_{t}^{k}+L_{t}+F_{t}=T R_{t}
$$

where $P_{t}^{k}$ denotes the price associated with adding to the stock of collection $k$, and $L_{t}$ and $F_{t}$ are labor and facility costs, which exist regardless of the library's decision to change collection stocks. Lastly, the term $T R_{t}$ represents a library's total operating revenue, consisting of public funds, fees, grants, and donations. 